Original Article

\title{
Biomechanical Analysis of Stair Descent in Patients with Knee Osteoarthritis
}

\author{
Tatsuya Igawa, PT, $\mathrm{PhD}^{1)^{*}}$, Junji Katsuhira, $\mathrm{PhD}^{1)}$ \\ 1) Department of Rehabilitation, International University of Health and Welfare Mita Hospital: 1-4-3 \\ Minato-ku, Tokyo 108-8329, Japan
}

\begin{abstract}
Purpose] The purposes of this study were to investigate the lower extremity joint kinematics and kinetics of patients with the knee osteoarthritis (knee OA) during stair descent and clarify the biomechanical factors related to their difficulty in stair descent. [Subjects and Methods] Eight healthy elderly persons and four knee OA patients participated in this study. A 3-D motion analysis system and force plates were employed to measure lower extremity joint angles, ranges of motion, joint moments, joint powers, and ratios of contribution for the joint powers while descending stairs. [Results] Knee joint flexion angle, extension moment, and negative power during the early stance phase in the knee OA group were smaller than those in the healthy subjects group. However, no significant changes in these parameters in the ankle joint were observed between the two subject groups. [Conclusion] Knee OA patients could not use the knee joint to absorb impact during the early stance phase of stair descent. Hence, they might compensate for the roles played by the intact knee joint by mainly using ipsilateral ankle kinematics and kinetics.

Key words: Knee osteoarthritis, Stair descent, 3-D motion analysis
\end{abstract}

(This article was submitted Jun. 6, 2013, and was accepted Jul. 3, 2013)

\section{INTRODUCTION}

Musculoskeletal diseases due to degenerative changes in bones and joints have tremendously increased with the rapid aging of the populations in developed countries ${ }^{1-3)}$. The estimated number of individuals with knee OA among musculoskeletal diseases is approximately 24 million in Ja$\mathrm{pan}^{4}$. Individuals with knee OA describe a variety of symptoms including knee pain, stiffness, and limited range of motion $^{5,6)}$. Development of symptomatic knee OA significantly restricts activities of daily living ${ }^{7)}$. Hence, knee OA is orthopedic disease causing daily life dysfunction. It is well known that stair descent predisposes the elderly to falling and is one of the most difficult activities during the early stage of knee OA patients. Accordingly, there is an urgent need to clarify the cause of the difficulty in stair descent in knee OA patients.

Some studies ${ }^{8-11)}$ have assessed stair descent in patients with knee OA. However, to date, no previous studies have conducted kinematic and kinetic analysis of stair descent in knee OA patients to clarify the biomechanical factors related to their difficulty in descending stairs. Therefore, the purposes of this study were to investigate the lower extremity joint kinematics and kinetics of patients with knee OA

*Corresponding author. Tatsuya Igawa (E-mail: t.igawa@, iuhw.ac.jp)

C2014 The Society of Physical Therapy Science. Published by IPEC Inc. This is an open-access article distributed under the terms of the Creative Commons Attribution Non-Commercial No Derivatives (by-ncnd) License $<$ http://creativecommons.org/licenses/by-nc-nd/3.0/>. during stair descent and clarify the biomechanical factors related to their difficulty in descending stairs.

\section{SUBJECTS AND METHODS}

The participants were four elderly individuals diagnosed with early stage unilateral knee OA (mean age, $76 \pm 7 \mathrm{yr}$; mean height, $150.2 \pm 5.4 \mathrm{~cm}$; mean weight, $55.4 \pm 8.4 \mathrm{~kg}$; a male and three females) and eight healthy elderly individuals (mean age, $69 \pm 6 \mathrm{yr}$; mean height, $154.7 \pm 2.5 \mathrm{~cm}$; mean weight, $56.5 \pm 4.9 \mathrm{~kg}$; five males and three females). All procedures were approved by the International University of Health and Welfare Research Ethics Committee, and participants provided written informed consent prior to enrollment. The severity of OA was assessed by using the Kellgren-Lawrence grading system ${ }^{12)}$. This study was performed on three patients and a patient who were diagnosed as grade IIand III, respectively. Subjects participated in the present study on a voluntary basis. A 3-D motion analysis system that included 12 infrared cameras (VICON 612; Vicon Motion Systems, Oxford, UK) and 6 force plates (AMTI, Watertown, MA, USA) were used to record kinematics and kinetics data at sample frequencies of 120 and $1080 \mathrm{~Hz}$, respectively. A total of 34 reflective markers with a diameter of $14 \mathrm{~mm}$ were attached to each subjects' body with reference to the report of Kito et al ${ }^{13)}$. Two staircases consisting of five steps were placed separately on either side of the force plates (one to the right and one to the left). This experimental setup made it possible to measure the floor reaction force individually for the right and left sides. The tread depth and riser height for both staircases were $300 \mathrm{~mm}$ and $160 \mathrm{~mm}$, respectively. All components of floor 
reaction forces were reset to zero to eliminate the effect of the weights of the staircases before initiating the experimental trials ${ }^{14)}$. All participants were instructed to descend while barefoot at a self-selected speed without any assistive devices. We measured kinematic and kinetic parameters of the dominant limbs of the elderly individuals and those of intact limbs of the knee OA subjects.

Lower extremity joint angles, ranges of motion, moments, powers, and the ratios of contribution of the powers were calculated for one gait cycle. Only the negative values of each joint power were used to determine the impact absorption in the early stance phase. Range of motion was also calculated in the early stance phase. We chose the mean peak value of these parameters in the three trials as the representative value for analysis.

Statistical significance was set at $p<0.05$. All data were analyzed with the SPSS 17.0 statistical software (SPSS Japan Inc., Tokyo, Japan). The Mann-Whitney-U test was used to compare the representative values described above between the two subject groups.

\section{RESULTS}

No significant changes in ankle joint kinematic parameters were observed between the two subject groups. The knee joint angle of knee OA subjects was smaller than that of the healthy elderly subjects during $12-23 \%$ of the gait cycle. The hip joint angle of the knee OA subjects was smaller than that of the healthy elderly subjects during $9-20 \%$ of the gait cycle (Table 1). Range of motion of the knee and hip joints of the knee OA subjects were smaller than those of the healthy elderly subjects (Table 2). Significant differences in ankle joint moment were observed between subject groups in $46-49 \%, 64-67 \%$, and $71-75 \%$ of the gait cycle. In addition, significant differences in knee and hip joint moments were observed during $7-27 \%$ and $38-40 \%$ of the gait cycle, respectively (Table 1). Significant differences in ankle, knee, and hip joint powers were observed between subject groups in $30-39 \%, 10-16 \%$, and $7-9 \%$ of the gait cycle, respectively (Table 1). The ratio of contribution of the knee joint power of the knee OA subjects was significantly smaller than that of the healthy elderly subjects, but this was not the case for the ankle and hip joint powers (Table 3 ).

\section{DISCUSSION}

Double knee action, which is mostly observed in level walking, has roles in impact absorption and weight bearing that move the center of gravity (COG) downward during stair descent ${ }^{15,16)}$. Kito et al. ${ }^{13)}$ reported that the action was almost completely gone during level walking in knee OA patients. In the present study, knee joint range of motion of knee OA patients was smaller than that of healthy elderly subjects while descending stairs, as reported in the case of level walking. In addition, negative power of the knee joint, indicating eccentric contraction of knee extensor muscles, was not exerted during the early stance phase in stair descent. For this reason, significant differences in ankle joint power were observed between the subject groups in $10-16 \%$ of the gait cycle. Also, knee OA subjects might not
Table 1. Significant differences in kinematic and kinetic parameters

\begin{tabular}{lrcc}
\hline & Angle & Moment & Power \\
\hline Ankle joint & & $46-49,64-67$ and $71-75 \%$ & $30-39 \%$ \\
Knee joint & $12-23 \%$ & $7-27 \%$ & $10-16 \%$ \\
Hip joint & $9-20 \%$ & $38-40 \%$ & $7-9 \%$ \\
\hline
\end{tabular}

Table 2. Range of motion of the lower extremities in the early stance phase

\begin{tabular}{lcrr}
\hline & Healthy elderly & Knee OA & \\
\hline Ankle joint (deg) & $34.5 \pm 3.6$ & $35.2 \pm 2.6$ & \\
Knee joint (deg) & $18.3 \pm 3.9$ & $11.3 \pm 2.0$ & $*$ \\
Hip joint (deg) & $4.8 \pm 0.8$ & $1.8 \pm 0.9$ & $*$ \\
\hline
\end{tabular}

$* \mathrm{p}<0.05$

Table 3. Ratios of contribution to power in the lower extremities in the early stance phase

\begin{tabular}{lccc}
\hline & Healthy elderly & Knee OA & \\
\hline Ankle joint (\%) & $45.3 \pm 8.1$ & $51.0 \pm 15.2$ & \\
Knee joint (\%) & $8.3 \pm 5.5$ & $1.5 \pm 1.8$ & $*$ \\
Hip joint (\%) & $4.4 \pm 3.4$ & $2.2 \pm 1.7$ & \\
\hline
\end{tabular}

$* \mathrm{p}<0.05$

be able to sufficiently absorb external impact force using the knee joint because the ratio of contribution of the knee joint power in them was smaller than that in healthy elderly subjects during the early stance phase. Other joints of ipsilateral limbs, that is, the ankle and the hip, could potentially compensate for the function of the intact knee joint and absorb the external impact force in this phase. But Muscles around the ankle joint would play a most prominent role in this phase. Eccentric contraction of ankle plantar flexor occur as a braking force of downward movement of COG. The ratios of contribution of the ankle joint power of the knee $\mathrm{OA}$ and healthy subjects were $51.0 \pm 15.2$ and $45.3 \pm 8.1$ in the early stance phase, respectively. These results might be a clue indicating ankle joint compensation for the intact knee joint in the early stance phase while descending stairs. Hip muscles complementarily absorbed external impact force in healthy subjects. The hip joint flexed at the same time that the knee joint absorbed external impact force. However, the hip joint range of motion of the knee OA subjects was significantly smaller than that of the healthy elderly subjects. The ratios of contribution of the hip joint power of the knee OA and healthy subjects were $2.2 \pm 1.7$ and $4.4 \pm 3.4$, respectively. Accordingly, negative hip joint power of the knee OA subjects was significantly smaller than that of the healthy subjects, and knee OA subjects might also have difficulty in using the hip joint to absorb external impact force in the early stance phase. These findings suggest that the main cause of difficulty of knee OA subjects could be observed in the early stance phase during stair descent.

The present study reported the differences in lower ex- 
tremity joint kinematics and kinetics during stair descent between healthy elderly and knee OA subjects. However, our study has several potential limitations. First, our study analyzed the kinetics and kinematics on the sagittal plane but not on the frontal and transverse planes. Second, we used a small number of knee OA subjects. Thus, further study should be performed with a larger number of knee OA patients and should clarify the biomechanical factors related to their difficulty in descending stairs on three-dimensional planes while descending stairs.

\section{REFERENCES}

1) Sharma L, Kapoor D, Issa S: Epidemiology of osteoarthritis: an update. Curr Opin Rheumatol, 2006, 18: 147-156. [Medline] [CrossRef]

2) Guccione AA, Felson DT, Anderson JJ, et al.: The effects of specific medical conditions on the functional limitations of elders in the Framingham Study. Am J Public Health, 1994, 84: 351-358. [Medline] [CrossRef]

3) Felson DT, Zhang Y: An update on the epidemiology of knee and hip osteoarthritis with a view to prevention. Arthritis Rheum, 1998, 41: 1343-1355. [Medline] [CrossRef]

4) Yoshimura N, Muraki S, Oka H, et al.: Prevalence of knee osteoarthritis, lumbar spondylosis, and osteoporosis in Japanese men and women: the research on osteoarthritis/osteoporosis against disability study. J Bone Miner Metab, 2009, 27: 620-628. [Medline] [CrossRef]

5) Hinman RS, Bennell KL, Metcalf BR, et al.: Delayed onset of quadriceps activity and altered knee joint kinematics during stair stepping in individuals with knee osteoarthritis. Arch Phys Med Rehabil, 2002, 83: 1080-1086. [Medline] [CrossRef]

6) Kaufman KR, Hughes C, Morrey BF, et al.: Gait characteristics of patients with knee osteoarthritis. J Biomech, 2001. 34: 907-915. [Medline] [CrossRef]
7) Jevsevar DS, Riley PO, Hodge WA, et al.: Knee kinematics and kinetics during locomotor activities of daily living in subjects with knee arthroplasty and in healthy control subjects. Phys Ther, 1993, 73: 229-239, discussion 240-242. [Medline]

8) Lessi GC, da Silva Serrão PR, Gimenez AC, et al.: Male subjects with early-stage knee osteoarthritis do not present biomechanical alterations in the sagittal plane during stair descent. Knee, 2012, 19: 387-391. [Medline] [CrossRef]

9) Hasegawa M, Chin T, Oki S, et al.: Effects of methods of descending stairs forwards versus backwards on knee joint force in patients with osteoarthritis of the knee: a clinical controlled study. Sports Med Arthrosc Rehabil Ther Technol, 2010, 2: 14. [Medline] [CrossRef]

10) Guo M, Axe MJ, Manal K: The influence of foot progression angle on the knee adduction moment during walking and stair climbing in pain free individuals with knee osteoarthritis. Gait Posture, 2007, 26: 436-441. [Medline] [CrossRef]

11) Liikavainio $\mathrm{T}$, Isolehto J, Helminen $\mathrm{HJ}$, et al.: Loading and gait symmetry during level and stair walking in asymptomatic subjects with knee osteoarthritis: importance of quadriceps femoris in reducing impact force during heel strike? Knee, 2007, 14: 231-238. [Medline] [CrossRef]

12) Kellgren JH, Lawrence JS: Radiological assessment of osteo-arthrosis Ann Rheum Dis, 1957, 16: 494-502. [Medline] [CrossRef]

13) Kito N, Shinkoda K, Yamasaki T, et al.: Contribution of knee adduction moment impulse to pain and disability in Japanese women with medial knee osteoarthritis. Clin Biomech (Bristol, Avon), 2010, 25: 914-919. [Medline] [CrossRef]

14) Katsuhira J, Yamamoto S, Asahara S, et al.: Comparison of the accuracy of measurement of floor reaction force and lower extremity joint moments calculated using different force plate measurement methods. J Phys Ther Sci, 2007, 19: 171-175. [CrossRef]

15) Zachazewski JE, Riley PO, Krebs DE: Biomechanical analysis of body mass transfer during stair ascent and descent of healthy subjects. J Rehabil Res Dev, 1993, 30: 412-422. [Medline]

16) Andriacchi TP, Andersson GB, Fermier RW, et al.: A study of lower-limb mechanics during stair-climbing. J Bone Joint Surg Am, 1980, 62: 749757. [Medline] 